\section{Opportunistic mimicry by a Jawfish}
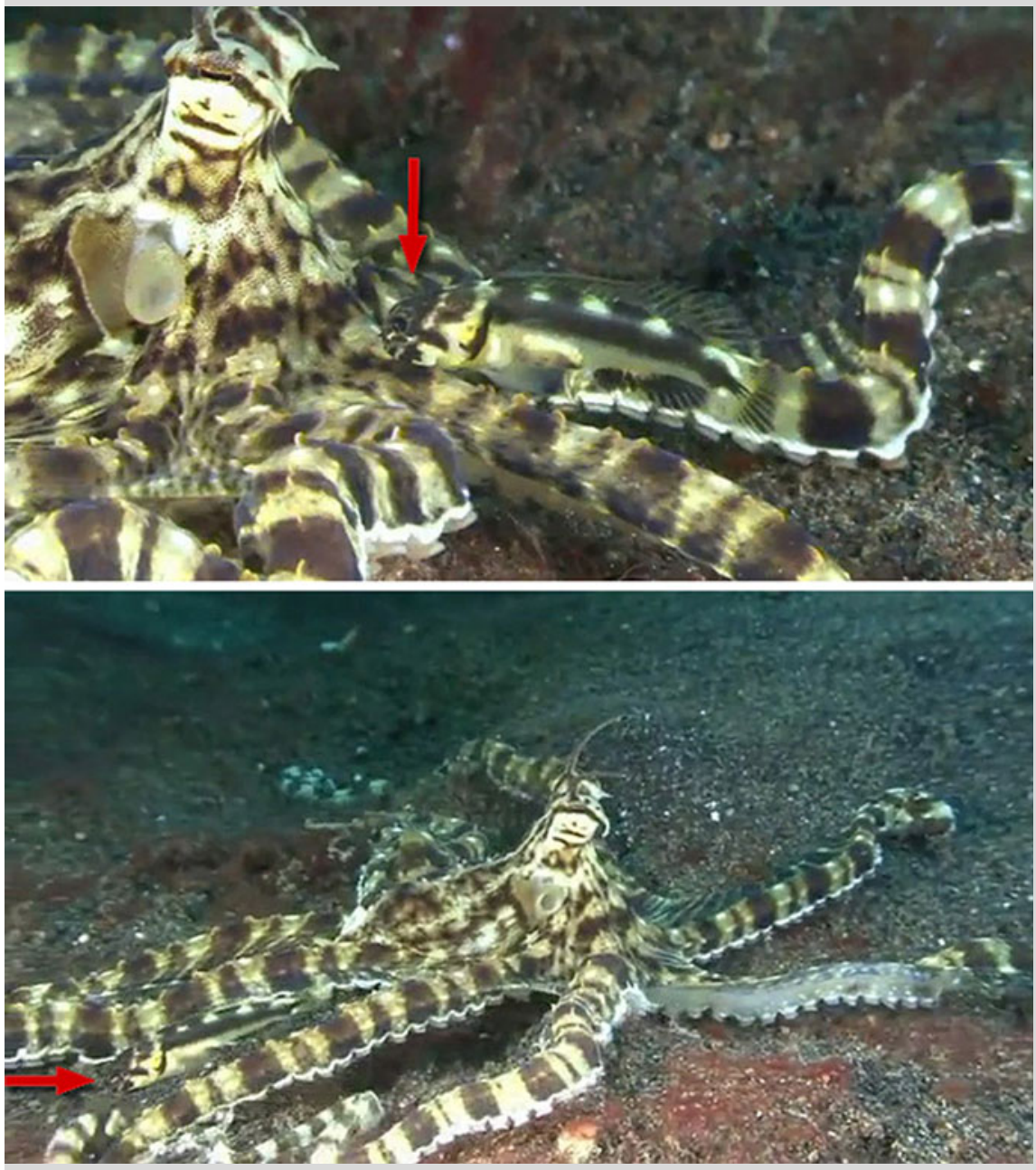

Fig. 1 Frames from the video showing the Black-Marble Jawfish (Stalix cf. histrio) closely following the Mimic Octopus (Thaumoctopus mimicus). Red arrows point to the head of the Jawfish. The entire video can be seen at http://www.youtube.com/watch?v=u4kZAgny5eg/$$
\text { (2005). In our case, we think the Black-Marble Jawfish takes advantage of the presence of the Mim }
$$

2005). In our case, we think the Black-Marble Jawfish takes advantage of the presence of the presumably to forage away from its shelter.

\section{References}

Cote IM, Cheney KL (2005) Animal mimicry: Choosing when to be a cleaner-fish mimic. Nature 433:211-212

Norman MD, Finn J, Tregenza T (2001) Dynamic mimicry in an Indo-Malayan octopus. Proc R Soc Lond B 268:1755-1758

Smith-Vaniz WF (1989) Revision of the jawfish genus Stalix (Pisces: Opistognathidae), with descriptions of four new species. Proc Acad Nat Sci Phil 141:375-407

Electronic supplementary material The online version of this article (doi:10.1007/s00338-011-0855-y) contains supplementary material, which is available to authorized users.

L. A. Rocha ( $₫)$

California Academy of Sciences, Section of Ichthyology, 55 Music Concourse Drive, San Francisco, CA 94118, USA

e-mail: LRocha@calacademy.org

R. Ross

California Academy of Sciences, Steinhart Aquarium, 55 Music Concourse Drive, San Francisco, CA 94118, USA

\section{G. Kopp}

Universität Göttingen, 37075 Gottingen, Germany

Received: 10 October 2011 / Accepted: 18 November 2011/Published online: 10 December 2011 (C) Springer-Verlag 2011 